\title{
EDITORIAL
}

\section{NUTRITIONAL ABNORMALITIES IN INFLAMMATORY BOWEL DISEASE}

\author{
Joel Faintuch
}

RHCFAP/3083

FAINTUCH J - Nutritional abnormalities in inflammatory bowel disease. Rev. Hosp. Clin. Fac. Med. S. Paulo 57(4):129130, 2002.

Few people would doubt that especial feeding procedures are an essential part of the therapeutic arsenal against Crohn's disease and ulcerative colitis. It must be recognized that many patients afflicted by these conditions either suffer from benign and self-limited modalities, or else respond favorably to medical or surgical treatment. In circumstances where acute episodes can be effectively curtailed and remissions are long, extending for years or decades, nutritional status tends to be comparatively well preserved and complex nutritional interventions are seldom needed.

For patients who are not so lucky, notably those exhibiting aggressive Crohn's disease, a long and miserable life is traditionally anticipated. Extended periods of exacerbation requiring or not hospitalization, frequent surgical maneuvers potentially resulting in visceral mutilation and temporary or permanent ostomy, anorectal infectious and inflammatory troubles, complications and comorbidities in distant organs and systems, and consumption of numerous and sometimes poorly tolerated drugs are a constant threat.

Anemia, hypoproteinemia and erosion of body energy and protein com- partments are hard to avoid in such a context, further interfering with the patient's ability to work, study, play, maintain social and family relations, and enjoy a healthy and rewarding life. Children pay an even higher price, not only because of the intrinsic psychological fragility and vulnerability of these organisms, but also because secondary malnutrition often results in growth arrest and stunting.

It is no coincidence that historically, many of the first candidates for home artificial nutrition suffered from digestive sequelae of Crohn's disease, and in some parts of the world they still represent one of the largest groups dependent on home care and long-term nutritional support ${ }^{1}$.

Among the first 50 surgical patients submitted to parenteral feeding in Hospital das Clinicas between 1971 and $1975^{2}$, mostly displaying gastrointestinal fistulas and abscesses, Crohn's disease was already quite prominent. Two particularly severe cases of high-output fistulas required

From the II Surgical Division - Surgery of the Digestive Tract, Department of Gastroenterology, Hospital das Clínicas, Faculty of Medicine, University of São Paulo. many months of alimentation via a central venous catheter before discharge. One of them was subsequently treated by home oral support and daily dressing changes during one year, until all fistulas healed, and the other required hospital admissions and additional periods of intravenous feeding during the next five years, because of persistent fever, diarrhea and abscesses.

Long term follow-up illustrates the vagaries of prognosis in inflammatory bowel disease. The first patient had 12 years of remission, only to succumb to colon cancer, whereas the other still suffers from occasional bouts of diarrhea, but is alive and well nearly 30 years after initial diagnosis.

The fundamental step towards improving the outlook of any clinical condition is elucidating its pathophysiology, and the sad truth is that to this date nobody has pinpointed the exact mechanism that triggers bowel damage in these chronic illnesses. The immune system is certainly involved, bacterial theories come and go every couple of decades, genetic influences cannot be denied, psychological factors have been strongly defended in the past, and a variety of other hypotheses can be found in the literature, but without single etiologic agents 
that are amenable to prophylaxis or neutralization ${ }^{3}$.

In spite of these shortcomings, surgical options have become less mutilating and more effective in recent years, new and powerful drugs have been introduced in the market, and last but not least, nutritional status has been markedly improved by intelligent application of oral, enteral and parenteral prescriptions. Even children with growth retardation often react with catch-up responses and enjoy the opportunity to achieve more acceptable adult height ${ }^{4}$.

During many years most of the discussions around nutritional care focused on the degree of hypermetabolism that is associated with inflammatory bowel disease, and as a corollary, on how much energy and protein one was supposed to administer in that context. It is unquestionable that somebody acutely affected by Crohn's abscesses and fistulas or by toxic megacolon secondary to ulcerative colitis can be markedly hypermetabolic, and may therefore require additional calories and notably a high nitrogen allowance in order to achieve nitrogen balance. The same is generally true in the immediate postoperative period, for individuals undergoing major operations such as total colectomy or extensive small bowel resections, although exaggerated intakes above $40 \mathrm{kcal} / \mathrm{kg} /$ day are avoided nowadays.

Whereas basic indications and modalities of especialized feeding for Crohn's disease, ulcerative colitis and their complications are quite obvious in the clinical routine, and present no great challenge to experienced medical teams, more transcendent doubts have been around for a number of years: 1) Do parenteral and enteral nutrition promote remission, and if yes, are the rates comparable to those achieved by corticosteroids and other anti-inflammatory drugs? 2) Is the beneficial impact of nutritional support linked to bowel rest, and if yes, which diet and route of administration should be preferred? 3) What is the role of omega- 6 , omega-3, medium- chain and short-chain fatty acids in the response to medical feedings? Is long-term supplementation or substitution of lipids desirable, after hospital discharge? 4) Are immune-stimulating preparations including glutamine and antioxidants better than standard formulations in this context?

These are meaningful details for chronic ailments that may accompany the patient during all his life, and although wrong dietetic options are not fraught with the same dangers as inappropriate drug regimens or unfortunate surgical procedures, they still involve potential deterioration of nutritional status and quality of life (or lack of improvement thereof), and not inconsiderable expense.

Not all of the nutritional issues have been squarely addressed in the article that follows ${ }^{5}$, which adopted a somewhat diferent approach, and in fact many ongoing investigations are still aiming to find the correct answers to some of these complex and relevant questions. In any case, the extensive and up-to-date review will shed precious light on the advantages and disadvantages of available dietetic alternatives. In this sense, it should contribute both to better understanding of the principles that govern nutritional assessment and therapeutic assistance in inflammatory bowel disease, and to safer and more successful results in the practical management of these subjects.

\section{REFERENCES}

1. HOWARD L \& HASSAN N - Home parenteral nutrition: 25 years later. Gastroenterol Clin North Am 1998; 27:481-512.

2. FAINTUCH J - Indicações e resultados em cirurgia geral. In: FAINTUCH J, MACHADO MCC, WRETLIND A et al (eds). Alimentação parenteral prolongada. São Paulo, Manole, 1976. p. $145-160$

3. HAN PD, BURKE A, BALDASSANO RN et al - Nutrition and inflammatory bowel disease. Gastroenterol Clin 1999; 28: 423-36.
4. MACK DR - Ongoing advances in inflammatory bowel diseases, including maintenance therapies, biologic agents, and biology of disease. Curr Opin Pediatr 1998; 10:499-506

5. CAMPOS FG, WAITZBERG DL, TEIXEIRA MG et al. Inflammatory bowel diseases. Principles of nutritional therapy. Rev Hosp Clín Fac Med S Paulo 2002; 57(4):187

Received for publication on March 18, 2002 